\title{
LEACHING KINETICS OF POWDERED PCB OF MOBILE PHONES IN $\mathrm{HNO}_{3}$ MEDIUM
}

\author{
Debarati Das ${ }^{1}$, Mahua Ghosh Chaudhuri ${ }^{2}$ \\ ${ }^{1,2}$ School of Materials Science \& Nanotechnology, Jadavpur University, India
}

\begin{abstract}
Printed circuit board (PCB) of mobile phones is leached in nitric acid $\left(\mathrm{HNO}_{3}\right)$ to extract the valuable metals present in $\mathrm{PCB}$ into the leaching solution. PCB powder is characterized by XRD analysis before and after leaching to identify the metallic phases present in it. It is found that precious metals gold (Au), silver (Ag), platinum (Pt), copper (Cu), lead (Pb), nickel (Ni) are present in the powder PCB before leaching. The leached solution is characterized by atomic absorption spectrometer (AAS). 0.0228\% Pb, $0.0448 \% \mathrm{Fe}$ and $0.047 \% \mathrm{Cu}$ are extracted in the solution. The leaching kinetics is also studied. Activation energy of the reaction is calculated $23 \mathrm{KJ}$ which suggest that the leaching reaction is diffusion controlled.
\end{abstract}

Keywords: PCB, Leaching Kinetics, XRD Analysis, AAS

\section{INTRODUCTION}

Electronic waste has been increasing rapidly with the development of technology. Nowadays, it is becoming necessary for recycling and disposal of these equipments. Precious metals like gold, platinum, copper, nickel, lead and iron are found in printed circuit board (PCB).

We use several classes of electronic devices on a regular basis, a huge portion of which is obsoleted very often with fast advancement of technology. Reuse of such disposed devices is important.

E-waste is a generic term encompassing various forms of electrical and electronic equipments (EEE) that are old,endof-life electronic appliances and have ceased to be of any value to their owners. [1] E-wastein general comprises of all old,end-of-life appliances like computers,laptops, audio and video products, refrigerators, freezers,mobiles phones etc. along with their peripherals. The sources of e-waste are relatively expensive and essentially durable products used for data processing, telecommunications or entertainment in private households and businesses. ${ }^{[2]}$

Mobile phone is a very useful electronic device in our modern life. With advancement of technology new models are coming into market and old models are becoming obsolete. This rapid change of mobile phones causing huge generation of E-waste as it is a common practice to throw away the old ones. Moreover, PCB of mobile phones contain valuable metals like $\mathrm{Au}, \mathrm{Ag}, \mathrm{Pt}, \mathrm{Pd}, \mathrm{Pb}, \mathrm{Cu}$, Ni.The natural source of these metals is limited so the recovery of precious metals from mobile PCB is very important.

Table 1 represents the amount of different valuable metals present in PCB of mobile phone as calculated by different scientists.

Table 1: Metal concentration (wt\%) of printed circuit boards reported in different studies. 3 ]

\begin{tabular}{|c|c|c|c|c|c|c|}
\hline $\mathrm{Wt} \%$ & $\begin{array}{c}\text { Sum et } \\
\mathrm{al}^{[4]}(2005)\end{array}$ & $\begin{array}{c}\text { Guo et } \\
\text { al[5](2009) }\end{array}$ & $\begin{array}{c}\text { Yang et al }{ }^{[6]} \\
(2009)\end{array}$ & $\begin{array}{l}\text { Park and Fray }{ }^{[7]} \\
(2009)\end{array}$ & $\begin{array}{c}\text { Yamane et al }{ }^{[8]} \\
(2011)\end{array}$ & $\begin{array}{c}\text { Tuncuk et al[9] } \\
\text { (2012) }\end{array}$ \\
\hline Gold & 0.1 & 0.008 & - & 0.025 & 0 & 0.035 \\
\hline Silver & 0.2 & 0.33 & - & 0.1 & 0.21 & 0.138 \\
\hline Copper & 20 & 26.8 & 25.06 & 16 & 34.49 & 13 \\
\hline Nickel & 2 & 0.47 & 0.0024 & 1 & 2,63 & 0.1 \\
\hline Tin & 4 & 1 & $\ldots$ & 3 & 3.39 & 0.5 \\
\hline
\end{tabular}


There are few routes for dissolution of metals from powder PCB. Mechanical, pyrometallurgical $\left.{ }^{[10}\right]^{-[11]}$ and hydrometallurgical $[9]$ processes are followed to recover and separate the metals from e-waste. In the present work, hydrometallurgical route is used to leach PCB of mobile phone.

PCB of mobile phones is leached using nitric acid $\left(\mathrm{HNO}_{3}\right)$ solution and the amount of the metals in the leached solution is measured by AAS. Finally, the kinetics of the leaching process is also carried out.

\section{MATERIALS AND METHOD}

\subsection{Sample Preparation}

Printed circuit board (PCB) of mobile phones is collected from China market, Kolkata. After collecting, they are cut into small pieces using metal cutter(Fig 1). Then the cut pieces are ground by mixer grinder into powder. The PCBs are ground to (-) 200 mesh are dried in air oven to remove moisture. The dried powder is thencalcined at $850^{\circ} \mathrm{C}$ to remove epoxy resin, plastics and other impurities. That calcined powder is then used for leaching and chemical analysis is carried out.
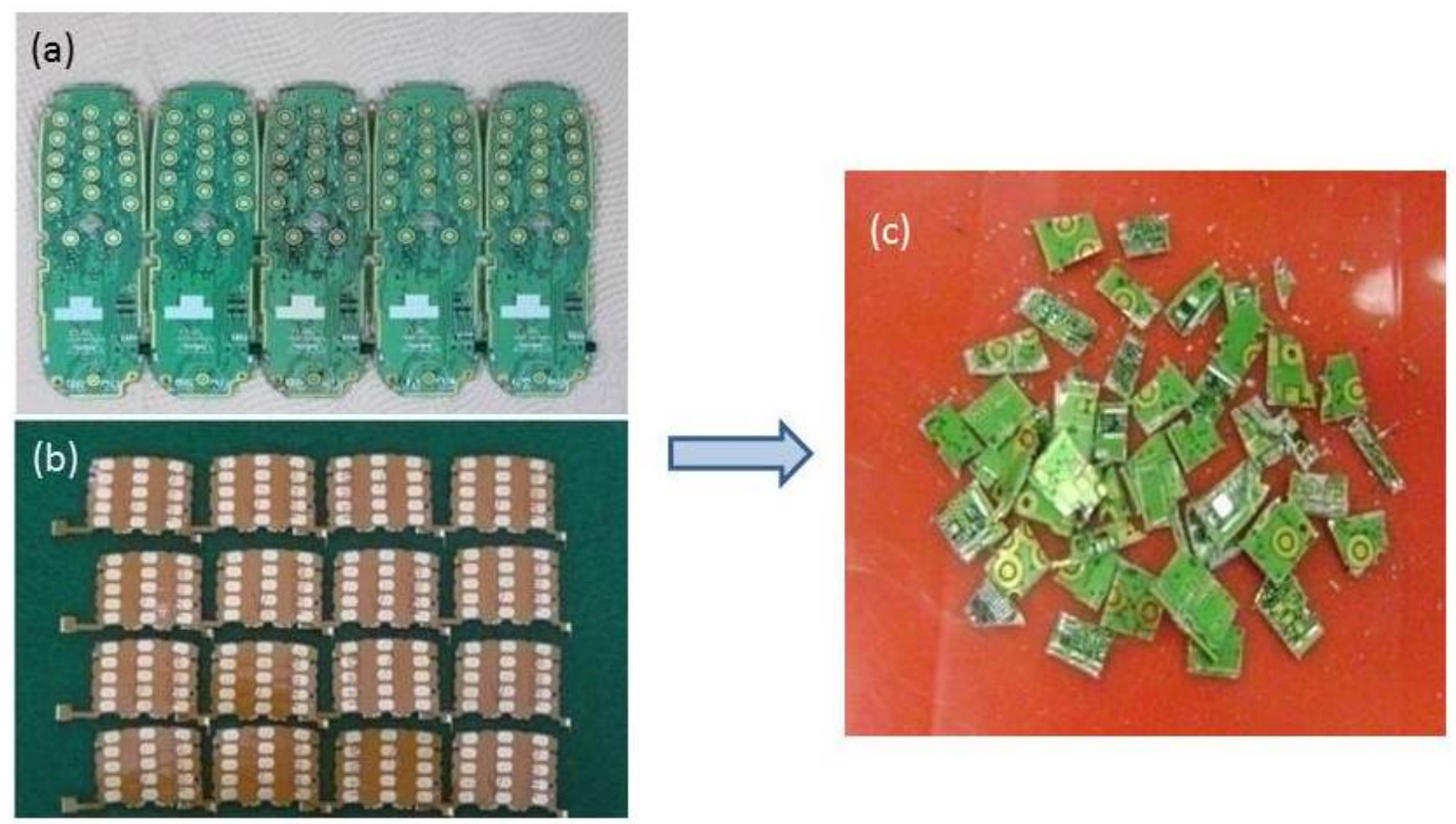

Fig 1: (a) Scraps (b) PCBs of waste mobile phones used for the experiment (c) Small picecs of mobile PCB

\subsection{Methodology}

\section{a) Leaching Process}

Leaching is a hydrometallurgical process used to bring the soluble components of solid into a solution from which the metal is extracted.Leaching can be described by the following equation:

Material (leachee) + leachant leachate

Leaching process of PCB powder is carried out in a $100 \mathrm{~mL}$ beaker using Nitric acid as leachant. PCB powder is placed in concentrated $\mathrm{HNO}_{3}$. The solution is stirred constantly and continued till it is dried. Then again $\mathrm{HNO}_{3}$ is added to get the remaining metals in solution. The entire green solution is filtered for $2-3$ hours using Wattmann 42 filter paper to remove the insoluble parts. The green filtrate is then transferred to a new beaker and the solution is made $250 \mathrm{ml}$ by addition of double distilled water. Finally the metal concentrations are determined using atomic absorption spectrophotometer. The solid-liquid ratio of PCB powder and nitric acid is 1:10. Fig. 2 represents the flow chart for dissolution of valuable metals from e-waste in nitric acid. 


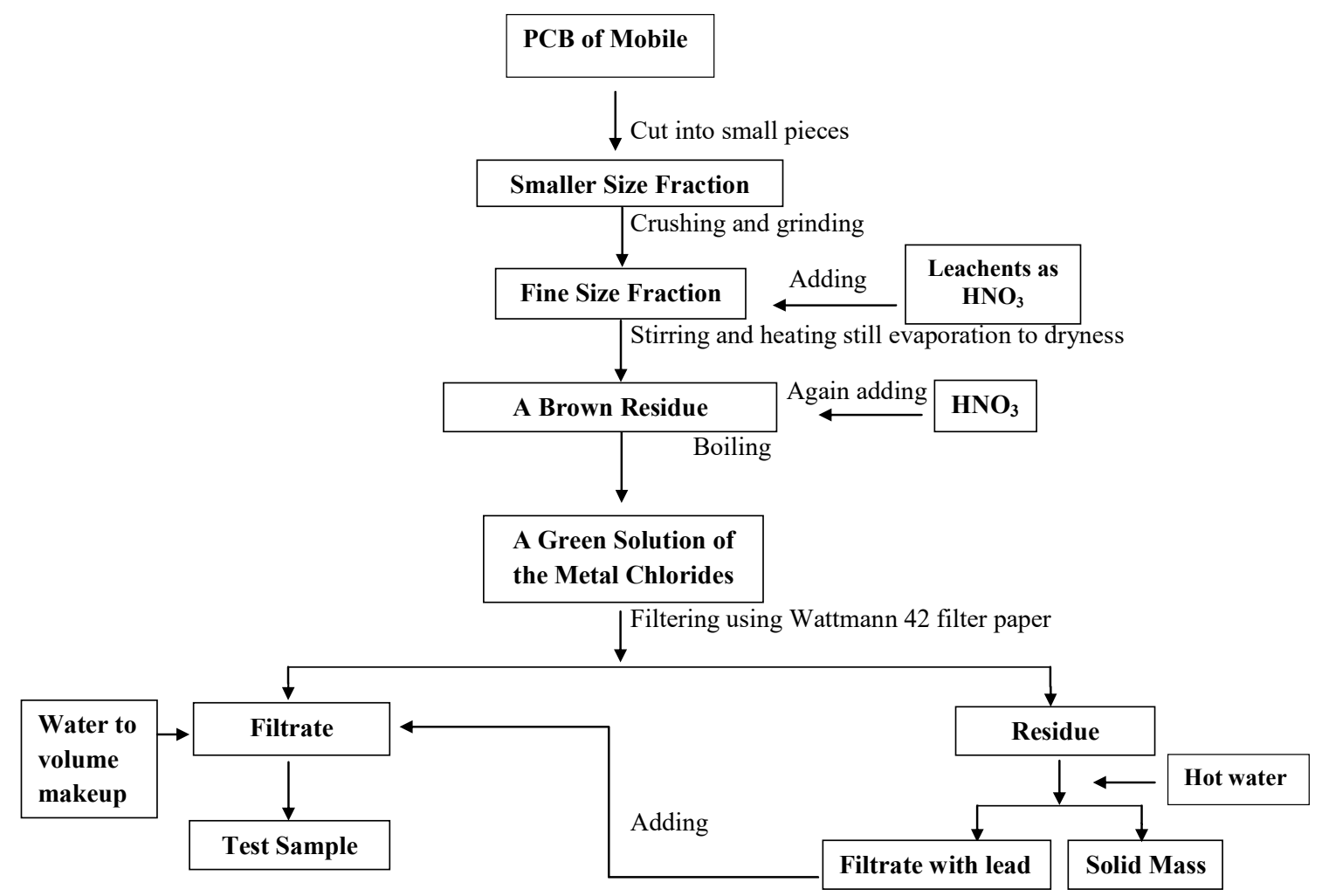

Fig 2: Flow Chart for assay of metal ions of $\mathrm{PCBs}$ using $\mathrm{HNO}_{3}$ as leachents

Phase analysis of the samples before and after leaching is carried by X-ray Diffractometer (RigakuUltima III). The samples are characterized by XRD with monochromatic $\mathrm{Cu}$ $\mathrm{K} \alpha$ radiation $\left(\lambda=1.4518 \mathrm{~A}^{\mathrm{o}}\right)$ in a continuous scan mode from 0 to $80^{\circ}$ at a scan rate of $5^{\circ} /$ minute.

Morphological study is investigated by Scanning Electron microscope (SEM, GEOL JSM-6360).

The concentration of the metal ion in solution is measured by atomic absorption spectrophotometer (A Analyst 200, Perkin Elmer).

\section{b) Kinetic Study}

Leaching of PCB powder is carried out in acidic medium using nitric acid as leachent. Nitric acid is mixed with double distilled water in the ratio $1: 9$ by volume. $2 \mathrm{gm}$ of PCB powder is added into $10 \mathrm{~mL}$ of nitric acid solution contained in a $250 \mathrm{~mL}$ Erlenmeyer flask. The flask is placed in a constant temperature water bath under constant stirring. The experiments are carried out at three different temperatures of $30^{\circ} \mathrm{C}, 50^{\circ} \mathrm{C}$ and $70^{\circ} \mathrm{C}$ for a time period of 5 hours. Leached solutions are withdrawn at an interval of 5 minutes. The concentration of metal ions in the leached solution is measured by AAS (A Analyst 200, Perkin Elmer). For kinetic analysis, the weight fraction of a particular metal in leached solution is calculated from AAS data and plotted as a function of time. In the present work, the kinetic behavior of leaching of the metallic fraction of Ewaste by $\mathrm{HNO}_{3}$ is reported.

\section{RESULTS AND DISCUSSION}

As powder $\mathrm{PCB}$ is added into $\mathrm{HNO}_{3}$ solution vigorous reactions start. $\mathrm{HNO}_{3}$ being a strong oxidizing agent oxidizes metals into nitrates. Table 2 gives the details of the metals which are leached and come into the solution.

Table 2: Concentration of the metals in the leached solution in nitric acid medium

\begin{tabular}{|c|c|c|c|c|}
\hline Metal Ions & Conc. & Pb & Fe & Cu \\
\hline $\mathrm{HNO}_{3}$ Medium & ppm & 0.247 & 0.638 & 0.376 \\
\cline { 2 - 5 } & $\mathrm{mg}$ & 0.6175 & 1.595 & 0.94 \\
\cline { 2 - 5 } & $\%$ & 0.0228 & 0.0448 & 0.047 \\
\hline
\end{tabular}

The reactions occurring in this leaching process are -

$$
\begin{aligned}
& 3 \mathrm{Cu}+8 \mathrm{HNO}_{3}=3 \mathrm{Cu}^{2+}+2 \mathrm{NO}+4 \mathrm{H}_{2} \mathrm{O}+6 \mathrm{NO}_{3}^{-} \\
& \mathrm{Pb}(\mathrm{s})+4 \mathrm{HNO}_{3}(\mathrm{aq})=\mathrm{Pb}\left(\mathrm{NO}_{3}\right)_{2}(\mathrm{aq})+2 \mathrm{H}_{2} \mathrm{O}(\mathrm{l})+2 \mathrm{NO}_{2}(\mathrm{~g}) \\
& 2 \mathrm{Fe}+6 \mathrm{HNO}_{3}=2 \mathrm{Fe}\left(\mathrm{NO}_{3}\right)_{3}+3 \mathrm{H}_{2}
\end{aligned}
$$

\section{a. X-ray Diffraction Analysis}

Phase analysis of the powder of printed circuit board is carried out by XRD as shown in Fig 3. However, noble metal gold $(\mathrm{Au})$ is present as $\mathrm{AuCu}$ metal phase. Also other precious metals like platinum $(\mathrm{Pt})$, nickel $(\mathrm{Ni})$, and iron $(\mathrm{Fe})$ and other metals present in trace amount. Fig 4 is the XRD plot of the residue after leaching the PCB powder by nitric acid. It is observed that $\mathrm{Ni}$ and $\mathrm{Cu}$ phase is present in the residue after leaching in the form of a complex. 


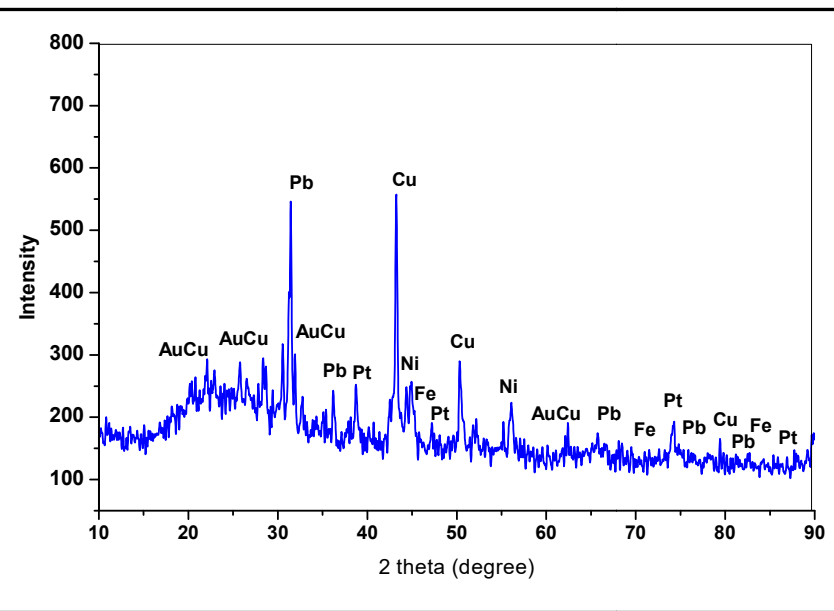

Figure 3: XRD pattern of raw powdered PCB

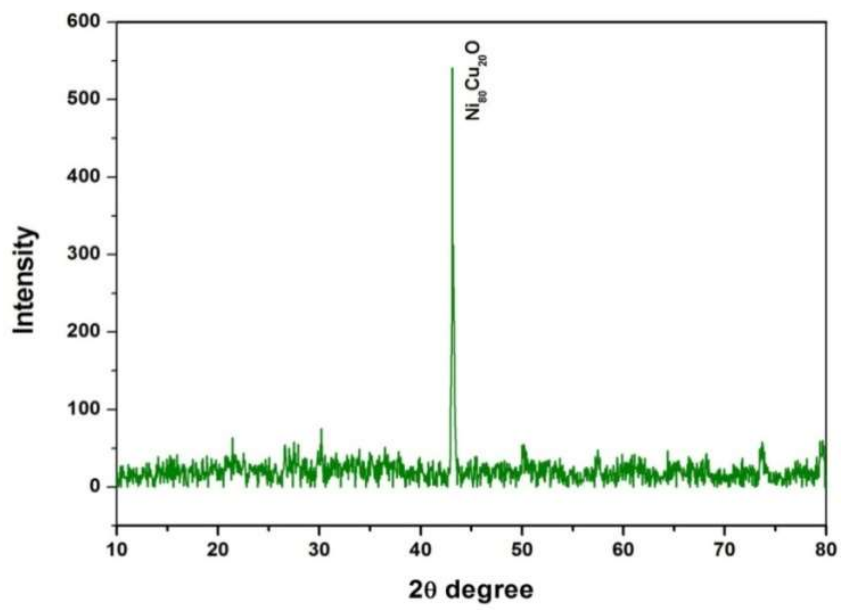

Figure 4: XRD pattern of the residue after leaching $\mathrm{PCB}$ sample in $\mathrm{HNO}_{3}$ medium

\section{b. Scanning Electron Microscopic Analysis}

The morphology of raw powdered PCB is shown in fig 5. The image shows rod shaped metals of around $10 \mu \mathrm{m}$ in diameter. After leaching by $\mathrm{HNO}_{3}$ the image (Fig.6) showssame rod like structure of the metal phase, but around $5 \mu \mathrm{m}$ in diameter which indicates that the rods are leached and they become thinner.

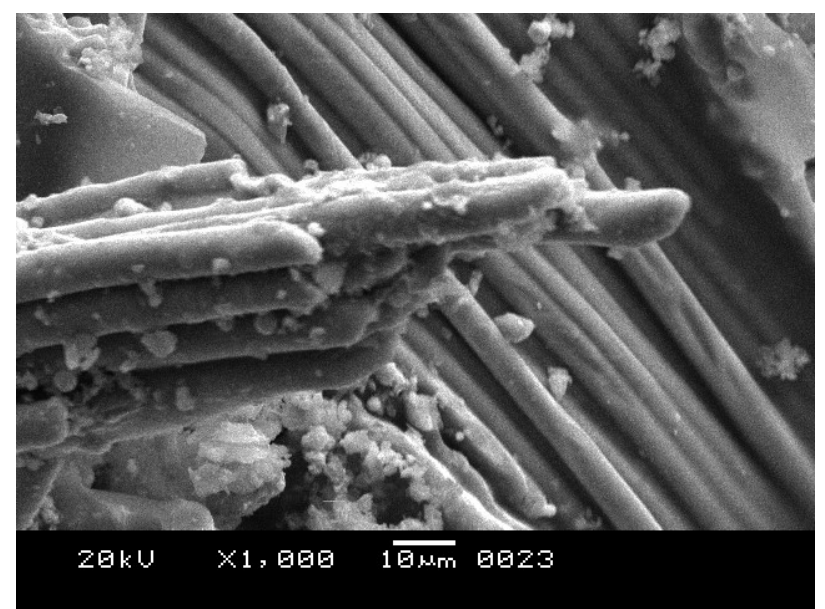

Fig 5: SEM image before leaching in $\mathrm{HNO}_{3}$ medium

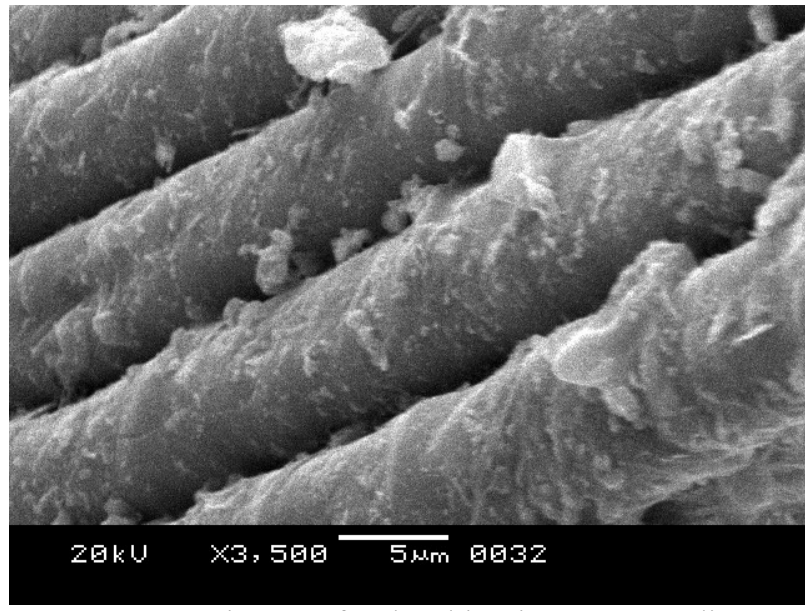

Fig 6: SEM image after leaching in $\mathrm{HNO}_{3}$ medium

\section{c. Study of Reaction Kinetics}

d.

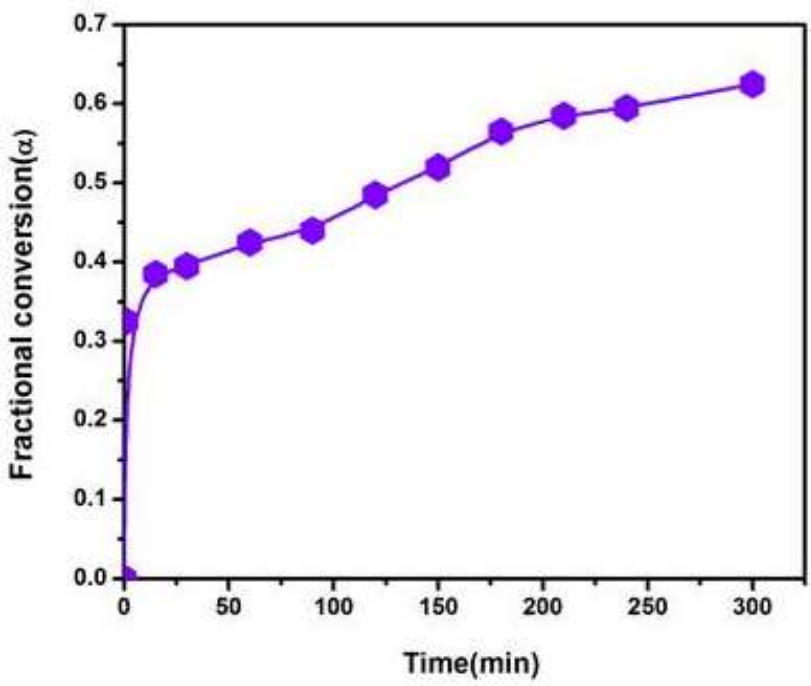

(a)

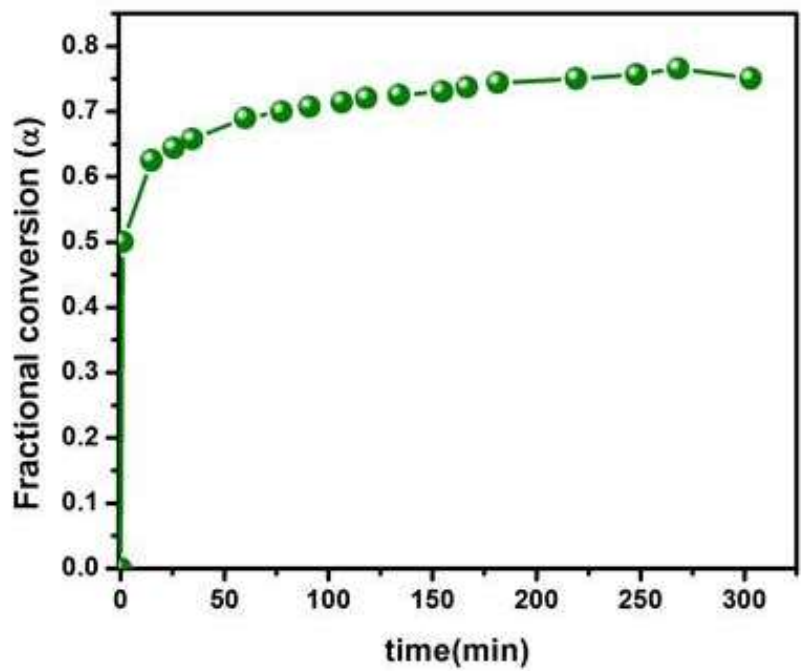

(b) 


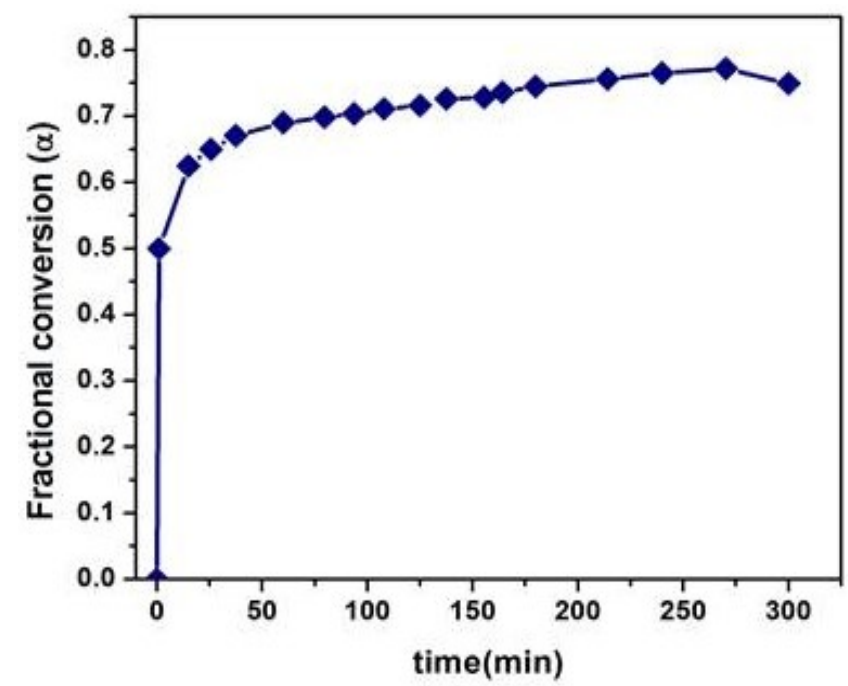

(c)

Fig 7: Fractional conversion $(\alpha)$ vs. time plot at different temperatures i.e. (a) $30^{\circ} \mathrm{C}$, (b) $50^{\circ} \mathrm{C}$, and (c) $70^{\circ} \mathrm{C}$ respectively using Conc. $\mathrm{HNO}_{3}$ medium

Fig 7 (a), (b) and (c) represents the plot of cumulative fractional conversion of all metals from E-waste to leached solution in acidic medium as a function of time for temperature $30^{\circ} \mathrm{C}, 50^{\circ} \mathrm{C}$ and $70^{\circ} \mathrm{C}$. From the reaction kinetic plots (Fig 7), the initial straight lines imply that the initial reaction rate is very fast at all the three temperatures and they gradually slow down with time. From each plot the slope $\mathrm{K}$ at that temperature is obtained. Arrhenius plot is constructed, which reflects the variation of $\mathrm{Ln} \mathrm{K}$ with $1 / \mathrm{T}$ where $\mathrm{T}$ is the temperature. Arrhenius plot is constructed as shown in Fig 8. From Arrhenius equation, $\mathrm{k}=\mathrm{Ae}^{(-\mathrm{Ea} / \mathrm{RT})}$, where $\mathrm{k}$ is the rate constant of the chemical reaction, $\mathrm{T}$ is the absolute temperature, $\mathrm{A}$ is the pre-exponential factor, $\mathrm{Ea}$ is the activation energy and $\mathrm{R}$ is the universal gas constant, the energy calculated which comes out to be $23 \mathrm{KJ} / \mathrm{mol}$. The regression coefficient value $\left(\mathrm{R}^{2}\right)$ is 0.91652 . The low activation energy of the leaching reaction implies that the leaching process is diffusion controlled.

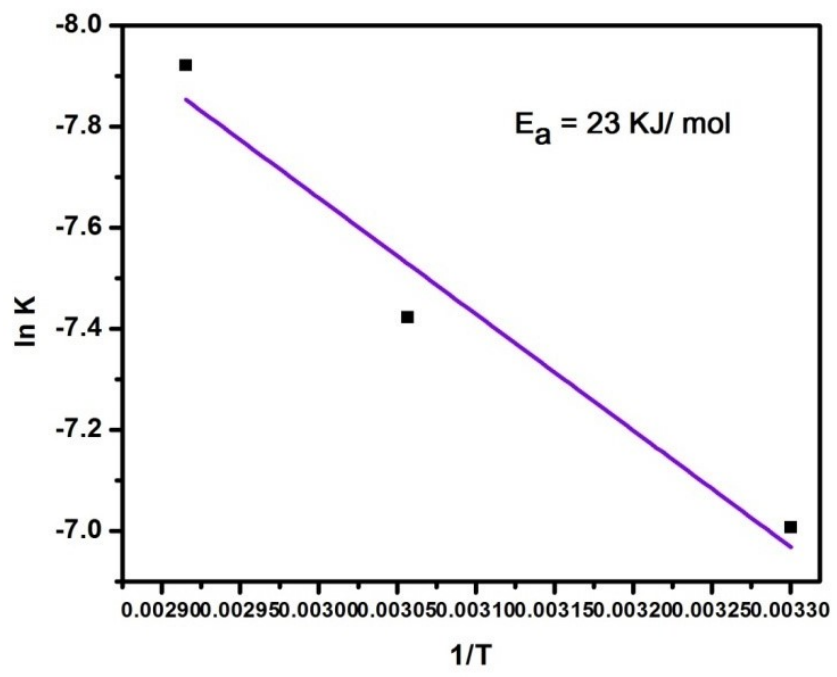

Fig 8: Arrhenius plot for extraction metals in $\mathrm{HNO}_{3}$ medium

\section{CONCLUSION}

PCB powder of mobile phones can be successfully leached with $\mathrm{HNO}_{3}$ and metallic iron, copper and lead are bought into solution. $0.0228 \% \mathrm{~Pb}, 0.0448 \% \mathrm{Fe}$ and $0.047 \% \mathrm{Cu}$ are extracted in the solution. The activation energy calculated from Arrhenius equation comes out to be $23 \mathrm{KJ} / \mathrm{mole}$. The low activation energy of the leaching process indicates that the leaching is diffusion controlled.

\section{REFERENCES}

[1] Mechanical recycling ofwaste electric and electronic equipment: a review,Cui J,Forssberg E, J. Hazard. Mater. 99 (3) (2003) 243-263.

[2] EPCEU, "Directive 2002/96/EC of the European Parliament and of the Council of 27 January 2003 on waste electrical and electronic equipment (WEEE), Off. J. Eur. Union L37 (2003) 24-38.

[3] Evaluation of gold and silver leaching from printed circuit board of cellphones, Petter P.M.H, Veit H.M, Bemardes A.M, Waste management 34 (2014) 475482.

[4] The recovery of metals from electronic scrap, Sum, E.Y.L., JOM 43 (2005), 53-61.

[5] Recycling of non-metallic fractions from waste printed boards: a review.Guo, J., Guo, J., Xu, Z., J. Hazard. Mater. 168 (2009) (2-3), 567-590.

[6] Factors influencing bioleaching copper from waste printed circuit boards by acidithiobacillusferroxidans.Yang, T., Xu, Z., Wen, J., Yang, L., Hydrometallurgy97 (2009) (1-2), 29-32.

[7] Recovery of high purity precious metals from printed circuit boards.Park, Y.J., Fray, D.J., J. Hazard. Mater. 164, (2009) 1152-1158.

[8] Recycling of WEEE:characterization of spent printed circuit boards from mobile phones andcomputers. Yamane, L.H., Moraes, V.T., Espinosa, D.C.R., Tenório, J.A.S., Waste Manage. (Oxford) 31, (2011) 2553-2558.

[9] Aqueous metal recovery techniques from e-scrap: hydrometallurgy in recycling.Tuncuk, A., Akcil, A., Yazici, E.Y., Devici, H., Miner. Eng. 25, (2012) 28-37.

[10] Improvising metal returns and eco-efficiency in electronics recycling - a holistic approach for interface optimization between preprocessing and integrated metals smelting and refining. In: IEEE International Symposium on Electronics \& the Environment. EUA, San Francisco,Hagelüken, C., (2006)a. 218-233.

[11] Recycling of electronic scrap at Umicore precious metalsrefining. Acta Metall. Slovaca 12,Hagelüken, C., (2006)b.111-120. 